University of Wollongong

Research Online

Faculty of Business - Papers (Archive)

Faculty of Business and Law

$1-1-2019$

In search of the "Right Price" for air travel: First steps towards estimating granular price-demand elasticity

Suranga Perera

University of New South Wales

David Tan

University of Wollongong, david_tan@uow.edu.au

Follow this and additional works at: https://ro.uow.edu.au/buspapers

Part of the Business Commons

Research Online is the open access institutional repository for the University of Wollongong. For further information contact the UOW Library: research-pubs@uow.edu.au 


\title{
In search of the "Right Price" for air travel: First steps towards estimating granular price-demand elasticity
}

\author{
Abstract \\ Identifying price-demand elasticity for air travel using empirical data is fraught with issues. The largest of \\ which is the problem of endogeneity. In this paper, we introduce instrumental variables derived from flow \\ traffic passenger numbers to overcome endogeneity. When analyzing the price-demand relationship using \\ flight date-point of sale and booking date-days to departure level data, flow traffic has the ideal property \\ of influencing ticket prices via an airline's inventory control function yet is uncorrelated with demand \\ shocks in the origin and destination market of interest. Ordinary least square (OLS) regression models \\ report that the demand of the given market is highly inelastic at -0.148 . Implementing the 2-Stage Least \\ Squares (2SLS) model with our proposed instruments, we find that demand is in fact elastic at -1.157 \\ which is consistent with industry observations. The proposed model is the first to estimate price elasticity \\ using granular level data combining revenue accounting coupons, booking and ticketing data. The \\ elasticity estimates account for endogeneity and granular characteristics such as days to departure, \\ booking and travel day of the week, point of sale, holidays and special events.

\section{Disciplines \\ Business}

\section{Publication Details} \\ Perera, S. \& Tan, D. (2019). In search of the "Right Price" for air travel: First steps towards estimating \\ granular price-demand elasticity. Transportation Research Part A: Policy and Practice, 130 557-569.
}




\title{
In Search of the "Right Price” for Air Travel: First Steps Towards Estimating Granular Price-Demand Elasticity
}

\author{
Suranga Perera ${ }^{\mathrm{a}}$ and David Tan ${ }^{\mathrm{a}, \mathrm{b}, *}$
}

\begin{abstract}
Identifying price-demand elasticity for air travel using empirical data is fraught with issues. The largest of which is the problem of endogeneity. In this paper, we introduce instrumental variables derived from flow traffic passenger numbers to overcome endogeneity. When analyzing the price-demand relationship using flight date-point of sale and booking date-days to departure level data, flow traffic has the ideal property of influencing ticket prices via an airline's inventory control function yet is uncorrelated with demand shocks in the origin and destination market of interest. Ordinary least square (OLS) regression models report that the demand of the given market is highly inelastic at -0.148. Implementing the 2-Stage Least Squares (2SLS) model with our proposed instruments, we find that demand is in fact elastic at -1.157 which is consistent with industry observations. The proposed model is the first to estimate price elasticity using granular level data combining revenue accounting coupons, booking and ticketing data. The elasticity estimates account for endogeneity and granular characteristics such as days to departure, booking and travel day of the week, point of sale, holidays and special events.
\end{abstract}

KEYWORDS: Price-demand elasticity; airfare; air travel; airline revenue management

a School of Aviation, University of New South Wales, Sydney, Australia

${ }^{\mathrm{b}}$ School of Accounting, Economics, \& Finance, University of Wollongong, Australia

* Corresponding author: Room 40.238, Faculty of Business, Northfields Ave Wollongong, NSW 2522, AUSTRALIA

Email address: david_tan@uow.edu.au 


\section{INTRODUCTION}

Achieving an optimal pricing outcome for any business requires a precise and comprehensive understanding of their customers purchasing behavior. This is particularly pertinent for a highly competitive and volatile industry such as aviation. Airline profit margins in general averaged +/- 5\% over a typical fiscal year (Morrel, 2013). Moreover, the return on invested capital (ROIC) of airlines have consistently underperformed relative to investor expectations (International Air Transport Association, 2013), which highlights the pressure faced by airlines to constantly strive to find avenues with which to increase revenue and lower costs.

Airlines possess the flexibility to manage multiple levers to reach optimal pricing outcomes and maximize revenue, where complex algorithms are implemented to create differential pricing and exploit market segment characteristics. However, the elemental concept in any optimal pricing model is determining the customers' conditional willingness to pay, otherwise known as price elasticity. Accurately estimating the price elasticity for the wide cross-section of air travelers at various times to departure is the holy grail of any airline revenue manager, as strategic and surgical price increases can be implemented without conceding market share (Weiss and Mehrotra, 2001; Puller and Taylor, 2012). Seetaram (2010) offers a critical analysis of the application of airfare price elasticity in the aviation/tourism literature and finds that there is little consensus on a reliable method of estimating such an elusive metric. Moreover, Seetaram (2010) reports that many researchers instead choose to ignore airfare price elasticity as the substantial measurement errors overweigh the omitted variable bias. Accurately estimating and understanding price elasticity will substantially increase the revenue optimization outcomes for an airline. For example, Fiig et. al (2009) report that revenue increases of $5-8 \%$ are attainable when more efficient revenue optimization methods are employed. Currie and Simpson (2007) assert that selecting the right price and fares distribution ladder can increase revenues by $4.8 \%$.

However, only a few applications exist today that attempt to utilize airline passenger elasticity as a direct input. Most applications relate to macro and market-summary analyses of policy decisions within the aviation and tourism sphere. At an airline level, it is difficult to measure air passenger price elasticity and implement it within revenue management due to two fundamental issues. First, disaggregated passenger ticket and booking data is often difficult for researchers to obtain, as such data are often proprietary and of high commercial value. Most academic research conducted on price elasticity, such as Njegovan (2006), employ public or market-level air passenger data and a broad price index in order to estimate elasticity. However, 
to be of any value to a revenue manager, price elasticity must be accurately estimated using a disaggregated level of data for specific flights and account for the days-to-departure, point-ofsale, day-of-week, traffic type (flow or point-to-point), passenger segment (e.g. public, government, students, infants) etc. The level of granularity required in a dataset to conduct such an analysis is demanding and often difficult for academics to acquire.

Second, price and passenger demand are both endogenously determined variables. Simply observing empirical data using standard OLS regression models will not produce accurate elasticity estimates, as prices are determined by expected passenger numbers and passenger numbers are strongly influenced by prices. In fact, the correlation coefficient of prices and tickets sold can be positive under this scenario (Lurkin et. al 2015) which is counter-intuitive and representative of the significance and magnitude of the endogeneity bias.

This study overcomes these inhibiting constraints on the estimation and implementation of price elasticity in airline revenue management. We work jointly with a major full-service network carrier based in Asia-Pacific to develop an econometric model that accurately estimates price elasticity at a level of detail and granularity that is useful to revenue managers. We combine revenue accounting coupon, sales ticketing and reservation booking data to generate a comprehensive dataset that contains key determinants of pricing and demand behavior, such as lead time to departure, time of travel, travel date, point of sale etc. The dataset has been developed based on the needs of the airlines and, thus, the analysis will yield results that can be directly beneficial to, and operationalized, by revenue managers.

This study overcomes the problem of endogeneity in the price of air travel by introducing instrumental variables that disaggregate exogenous price changes from those induced by expected demand. Due to the detail of the revenue accounting coupon and ticketing data available to us, we are able to identify passengers whose travels extend beyond the origindestination ports of the flight ("flow traffic") and those passengers who are embarking and disembarking at the origin/destination ("point-to-point traffic”). The bid-price inventory control mechanism employed by the airline generates the relation between the number of seats already purchased and the hurdle (required) price for the subsequent available seat to be sold. Combined with the inventory control mechanism, flow passengers are related to the ticket prices of pointto-point passengers as they occupy seats on the flight. Airlines, in practice, assess demand and price tickets for differing Origin and Destination (O\&D) markets independently. As such, demand (bookings) in the flow traffic markets at time $t$ are orthogonal to the point-to-point 
market as flow traffic consists of a portfolio of routes (aggregated at time $t$ ) with different O\&D markets excluding the point-to-point O\&D market.

Using a 2-Stage Least Squares (2SLS) framework, we are able to quantify the changes in ticket demand due to exogenous movement in airfares, and thus produce accurate estimates of price elasticity. Our modelling procedure controls for time to departure, booking and travel day of week, seasonality, passenger segmentation at fare-product level and city point of sale. The proposed flow traffic instruments are found to be correlated to point-to-point O\&D airfares when estimating the first-stage regressions. Due to airlines treating different O\&Ds as separate and independent markets, using a portfolio of flow passenger demand in different O\&D markets will theoretically be orthogonal to the point-to-point O\&D market. We find support of orthogonality using correlation tests and the Sargan (1988) test for overidentification.

Using an OLS regression model, we find evidence that the elasticity for air travel on the route under study is highly inelastic, with an estimated elasticity value of -0.148 . However, this result is vulnerable to endogeneity as airfares are dependent on expected demand and demand shocks, and other unobservable factors specific to the point-to-point market of interest that may influence passenger demand. We employ a 2SLS approach using flow traffic (passengers travelling beyond the point-to-point $\mathrm{O} \& \mathrm{D}$ market of interest) as it is correlated to airfares, yet the portfolio of flow traffic demand is largely orthogonal to the O\&D demand shocks. The 2SLS estimate of elasticity is -1.157 which is in line with what revenue practitioners at our partner airline would expect for the selected route - that is, for demand to be sensitive to price changes. Mumbower et al (2014) and Lurkin et al (2017) reported similar differences between 2SLS price elasticity estimates and those that do not control for endogeneity. The elasticity estimates of the current study employ flight date-point of sale and booking date-days to departure level instrumental variables and have accounted for micro characteristics such as days to departure, booking and travel day of the week, point of sale, and public holidays/special events when estimating demand. Moreover, we use all channels of sales distribution, including the airline's website, partner websites, travel agents, ticket offices, etc. We test for the strength and validity of the instrument set and find that it is indeed appropriate. This study also identifies ideal scenarios ( flight load and flow traffic characteristics) that will produce accurate estimates of the O\&D elasticity.

This paper is organized as follows: Section 2 addresses the identification issues and how these have been approached in the aviation economics literature; Section 3 discusses the data source 
and descriptive statistics of our sample; Section 4 presents a discussion on the inventory control mechanism of airlines relevant to the study; Section 5 introduces the proposed instrumental variables and their rationale; Section 6 details the econometric model; Section 7 provides a discussion on ideal conditions for the model; Section 8 presents the results of the modelling process and diagnostic tests; and Section 9 concludes the study.

\section{BACKGROUND LITERATURE AND ISSUES}

The primary cause of endogeneity in the modelling of the price-demand relationship in the airline context is simultaneity. Simultaneity occurs when price influences demand and demand, in turn, has an impact on price. This is likely as revenue managers often set ticket prices based on forecasted demand ${ }^{1}$, which results in expected ticket demand being a determinant of the regressor of interest - ticket price. As Revenue Management Systems (RMS) become increasingly more sophisticated and the boundary between inventory and pricing processes disappear, this source of endogeneity will have a larger impact (bias) on elasticity estimates due to the joint responsiveness of pricing and demand.

It is commonly found in the literature (Lurkin et al., 2017; Guevara and Polanco, 2016; Mumbower et al., 2014; and Grandos et al., 2012) that when endogeneity is ignored in the pricedemand relationship, nonsensical elasticity values that are incongruent with practical observations are produced, such as positive elasticity estimates. It is common that highly elastic sectors that are well-known by practitioners may produce inelastic or positive estimates if the inherent endogeneity problem is not adequately addressed.

According to Lurkin et al. (2015), many empirical price-demand studies have shown that price coefficients are underestimated if endogeneity remains unaccounted for. This is a phenomenon that is prevalent across many industries ${ }^{2}$. Recent studies by Mumbower (2014) and Lurkin et al. (2017) focused on negating the effects of endogeneity in modelling airline price-demand elasticity by employing instrumental variables. Both studies employ broad measures as instruments, such as structural characteristics (e.g. distance of rival routes), Hausman-type instruments (e.g. the average airfare for all other markets of similar length by an airline), costshifting variables (e.g. spikes in prices of fuel), and competition measures (e.g. number of

\footnotetext{
${ }^{1}$ Based on revenue management system forecasts and the current held bookings

${ }^{2}$ See Mumbower (2014) for an excellent account of recent studies on estimating elasticity in various industries
} 
carriers servicing the route or a Herfindhal index of market concentration). Though these instruments have proven to be effective in deriving unbiased airline price-demand elasticity measures, the broad route-level instruments employed produce elasticity estimates that vary at the route-level only, not at the granular flight date-point of sale and booking date-days to departure level.

The current study is a first step towards estimating elasticity measures that vary with passenger characteristics, time to departure, booking and travel day of the week, and other micro-variables. The proposed model estimates an unbiased elasticity measure using flight date-point of sale and booking date-days to departure level data. This paves the way for future research where elasticity measures can interact with passenger variables and provide granular and dynamic elasticity estimates. For example, elasticity estimates that vary as the departure date approaches.

We employ revenue accounting coupon and ticketing data that contain all sales channels, extending beyond online channels. Further, we are able merge passenger booking information resulting in a "days purchased prior to departure" measure for all sales channels. The other important distinction of this study is its alignment with modern RMS methodologies as it is conducted jointly with a large full-service network carrier. We map the fare products (fare basis codes) of passenger tickets to passenger-type categories, such as public, corporate, student, government, etc. The development of the variables and econometric models are consistent with the existing RMS of the partner airline, and hence, the devised methodology can be applied directly by practitioners. For example, the "days purchased prior to departure” categories, holidays and special event dummy variables are those used by the RMS of a full-service network carrier.

\section{DATA}

We merge three existing databases of an airline to create the dataset for this study, namely:

1. Booking data (Passenger Name Record - PNR data) for capturing the booking date and time, of a purchased ticket

2. Ticketing data to map the end-to-end ticket value of flow passengers

3. Revenue accounting coupon data to gather all other information, such as the point-topoint segment value including all the commissions, fare product, flight/ travel times, etc.

In general, booking data resides in the reservation system (RES), coupon data in revenue accounting (RA) system and the ticketing data in the revenue accounting (RA)/ ticketing 
systems of an airline. Historically, these systems are completely independent. Merging these datasets is a difficult task due to the specificity of their respective systems.

The coupon and ticketing data fields from the RA system database of a major Asia-Pacific based carrier is the primary source of data for this study. This is due to the precision in its pricing information as it contains the price observed by passengers at the time of purchase. The RA system segments the fare products as implemented in practice, and the number of passengers carried is defined by the fulfilment of payment and their flown status. The PNR database allows us to determine the booking date and time for each ticket. We demarcate various passenger segments using the fare product information on the tickets. Using the fare basis codes of each passenger coupon, we link each purchase to a limited set of fare product groups. These groups represent typical passenger segments used by airlines such as public, private, corporate, student, child, infant, frequent flyer, wholesale, government, other airlines, partner airlines, and so on.

Given the detailed booking and ticketing information available to this study, we are able to incorporate the following variables in the model:

1. Departure Day of Week - Derived from the travel date, we create day of week (DoW) dummy variables. These will account for any fixed effects in ticket demand across days of the week.

2. Point of Sale (POS) City - For flight origin and destination markets, the actual point of sale is used, and are labelled as POSCityBBB and POSCityAAA, respectively. Most bookings (greater than $80 \%$ in our dataset) are generated by the origin and destination markets. The POS variables for other major cities are also included as controls.

3. Fare Product Group - We categorize the fare products (referred as fare basis codes in practice) used in the ticket sales to categorize the travelers. These broad fare product groups (e.g. public, corporate, student, wholesale etc) in each cabin are used to demarcate the segments of interest. In this study, we consider the public fare paying passengers to model elasticity and assume that the market structure (proportion of public fare paying passengers to total passengers) remains consistent throughout the study period.

4. Seasonality - Dummy variables are employed for seasonal dates aligning with the airline’s RMS, e.g. standard peak periods, holidays and special events etc.

5. Days Prior to Departure - Days prior to departure is calculated as the travel date minus the booking date (the seat confirmation date in the inventory as recorded in the PNR database). We employ the same classification structure as the airline's RMS and 
categorize Days Prior into defined ranges leading up to departure, referred to as Data Capturing Points (DCPs). The purpose of DCPs is to divide the booking period (0 to 355 days) into intervals during which the arrival rate of bookings has been historically constant. Equivalently, the DCPs represent the points at which the rate of booking arrivals changes substantially. The optimal selection of DCPs will handle changes in the arrival rate throughout the booking period while minimizing the variability in the observations. Less variability improves forecast accuracy of the RMS and aids in the detection of holidays, seasonality, and trend effects. The change points in the arrival process (i.e. the DCPs) are detected using the multiple regression method described by McLaren et al. (2000). We use the same structure in this study. The DCP ranges as defined by the RMS are presented in Table A1 of the Appendix.

6. Traffic Type - We identify whether a passenger is a direct or connecting traveler between the origin and destination markets by using the O\&D identifiers in the booking and revenue accounting data. We use segment $O \& D$, online $O \& D$ and geographical $O \& D$ to verify if a passenger is a direct or connecting traveler. This distinction is crucial in the formation of the proposed instrumental variables.

The flight number can be included as a control variable. However, in the current study only one flight number exists for the airline and market under consideration. In other applications of this model, dummy variables for flight numbers can be included to account for any fixed differences in demand for specific flight timings in the route of interest.

Panel A of Figure 1 below presents the boxplots of the distribution of total point-to-point demand for publicly available adult passenger fare products over a period of 12 months during a normal booking period (excluding major flight disruptions) for all POS markets. Panels B and $\mathrm{C}$ presents the distributions across day-of-week and POS for the same dataset, respectively. We can see that the majority of bookings are received further from the departure date, and that passenger booking behavior (frequency) alters substantially as the departure date approaches. There is less variation in booking behavior at the day of the week level. The point of sale distribution of bookings suggests that there are three major markets (POS3 is a substantial point of sale outside origin and destination markets). These variables will be accounted/controlled for in the point of sale-flight and booking dates-days to departure level modelling as frequency in booking is likely linked to purchase behavior. 


\section{Figure 1: Distribution of Demand based on Data Capturing Point, Day of Week and Point}

\section{of Sale}

The boxplot below presents the graph of the natural logarithm of demand of total point-to-point passengers who purchased publicly available adult fare products over a period of 12 months during a normal booking period (excluding major flight disruptions) for 19 categories of DCP date-ranges for all points of sale. Days prior to departure is calculated as the travel date minus the booking date (the last update of the booking or the seat confirmation calculation date in the inventory as recorded in the Passenger Name Record). The purpose of DCPs is to divide the booking period ( 0 to 355 days) into intervals during which the arrival rate is constant. Equivalently, the DCPs should be the change points in the arrival process, i.e. the points at which the arrival rate changes. DCP1 is the start of booking window and DCP19 is the departure date. In our sample, DCP1 = 355 days prior to departure to 251 days prior to departure range. The widths of the DCP categories are aligned with the RMS setting which is specific to our partner airline. The graph shows that most of the passenger demand occurs before DCP11. Also shown are day of week (DoW) variation and Point-Of-Sale (POS) variation of the demand distribution. POS is aggregated based on the significance of the origin and destination points and we term Origin as Point of Commencement 1 (POC1) and Destination as Point of Commencement 2 (POC2) and rest of the world (ROW). In our sample there is a third country that is selling a significant amount of tickets which we identify as POS3. There are 19703 observations considered in this sample.

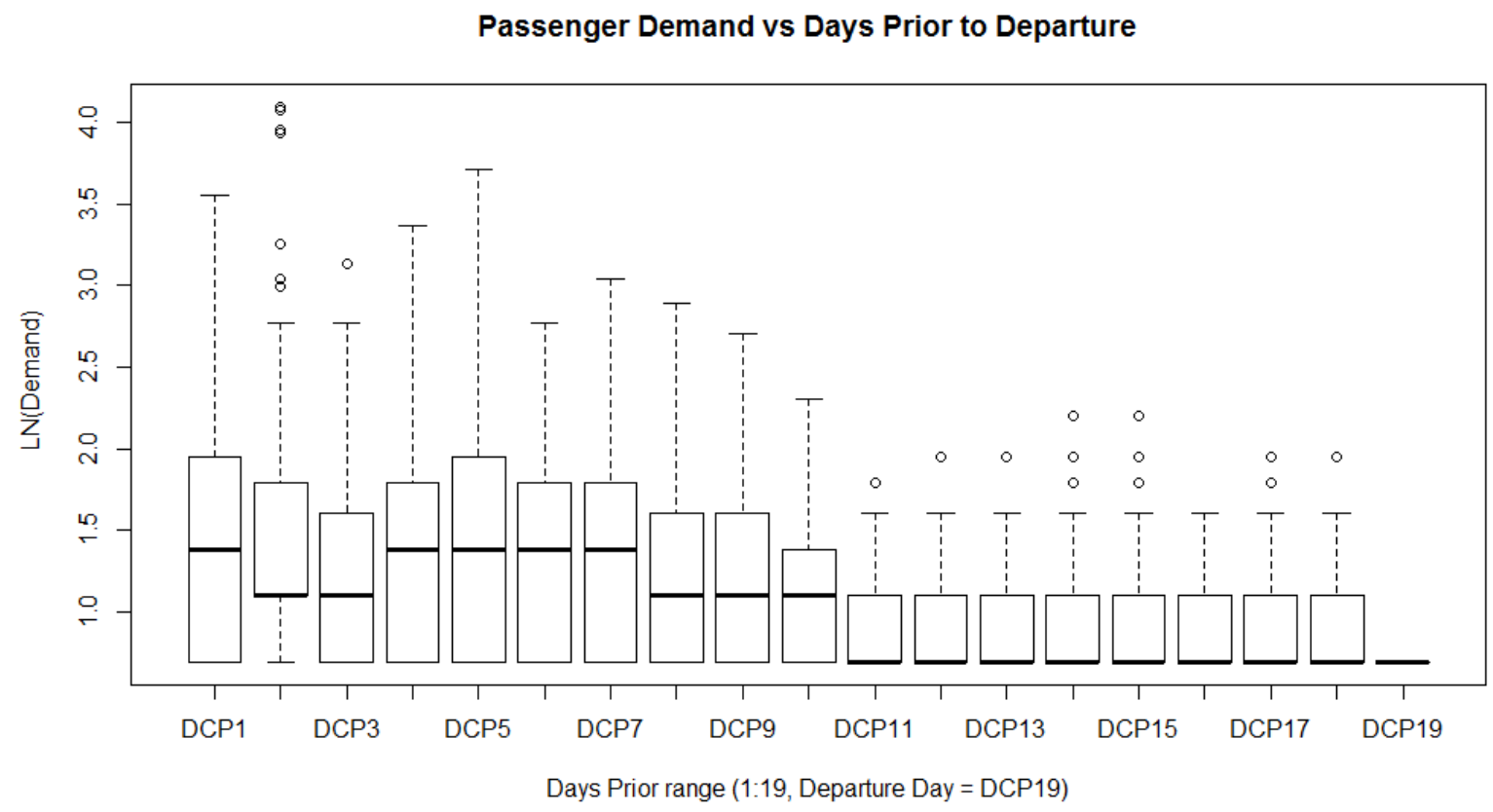


Passenger Demand vs Day of Week

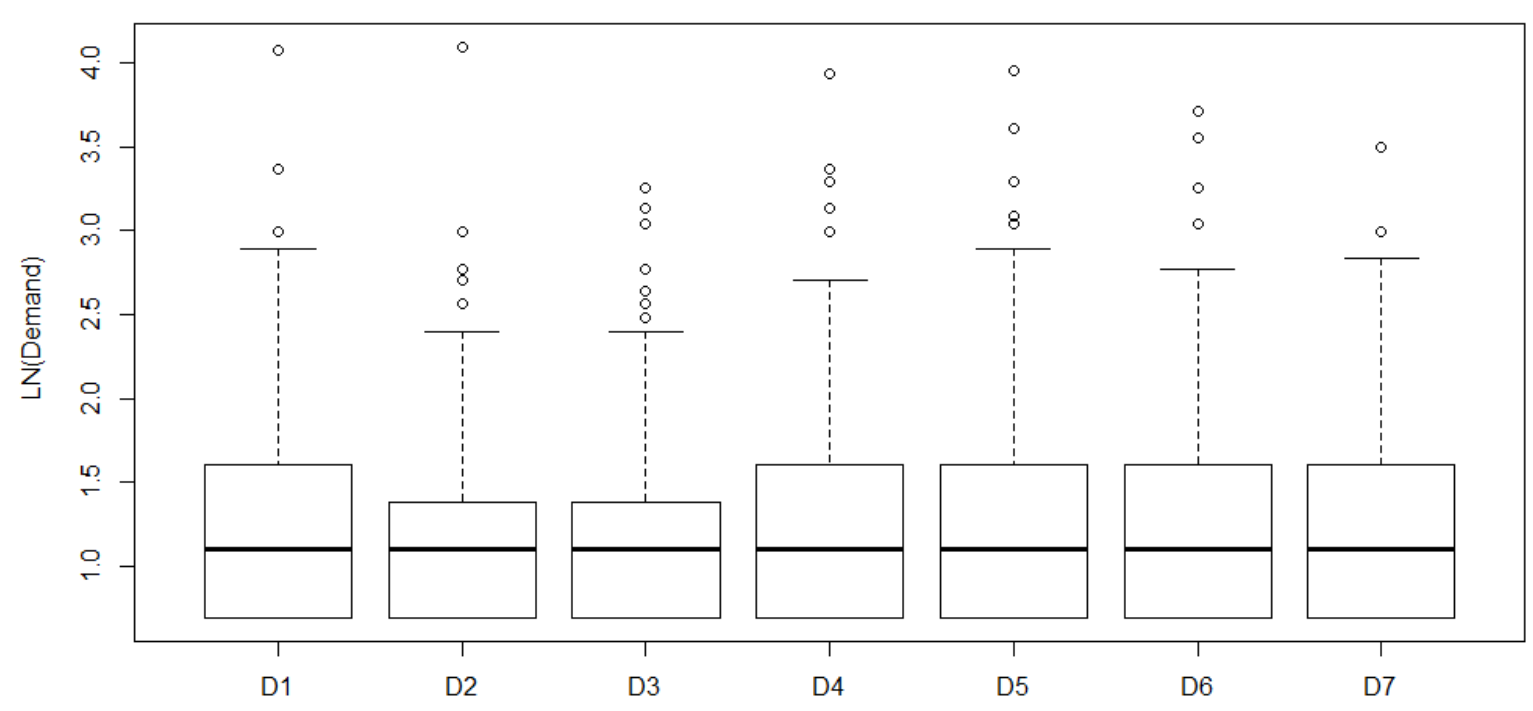

Day of Week (D1 = Monday,D2 = Tuesday,D3 = Wednesday,D4 = Thursday, D5 = Friday,D6 = Saturday,D7 = Sunday )

Passenger Demand vs Point of Sale

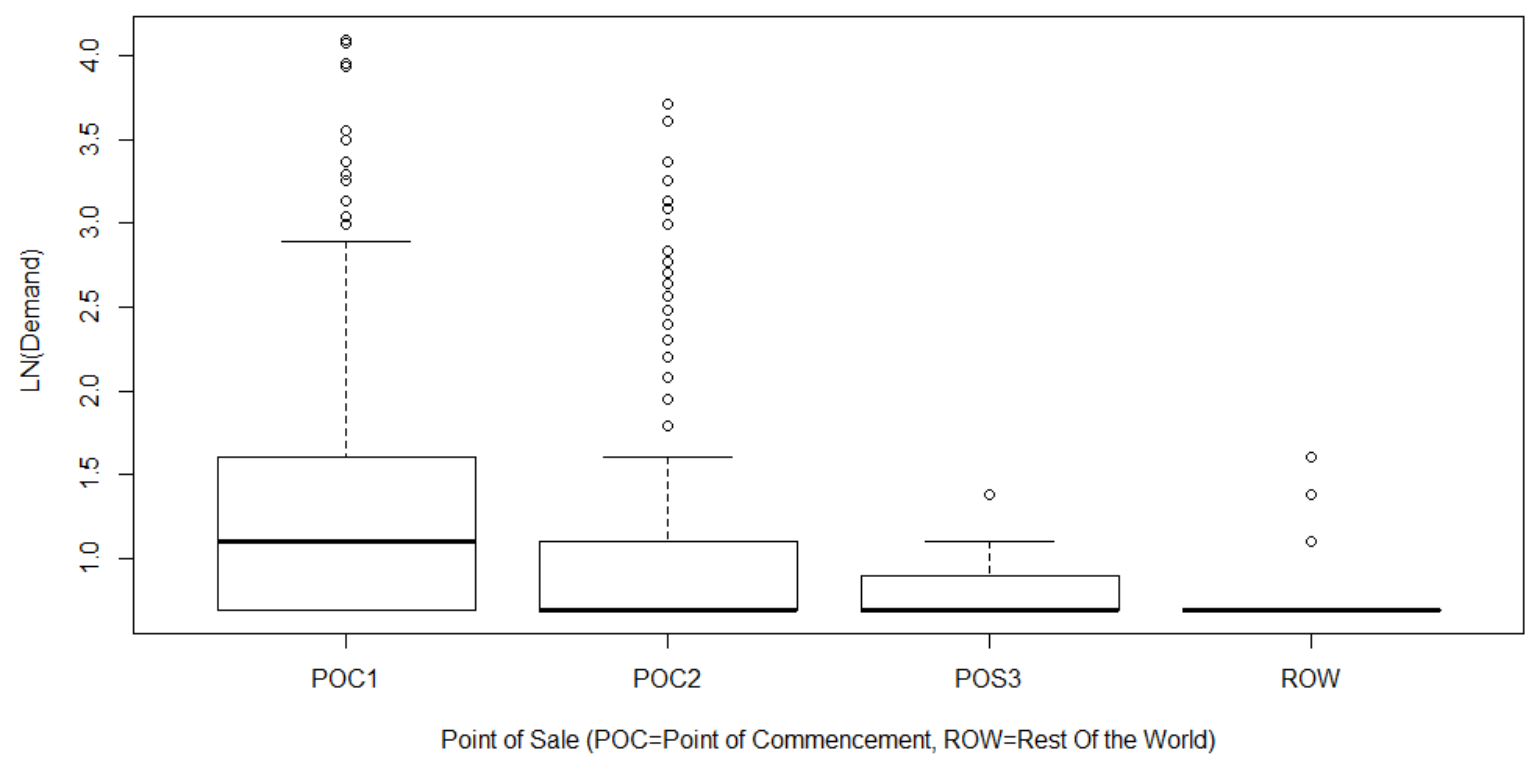

Page 9 of 30 


\section{INVENTORY CONTROL FUNCTION}

Airlines control seat inventory by two popular methods, namely:

(1). Class based controls or (2). Revenue based bid price control

Until recently, simple class-based controls were popular. These systems limit seat availability at the booking class level in order to manage the number of seats allocated for the given fare/s in a class. The classes are linked in a hierarchical structure based on the ticket prices of each class. This allows the inventory to be closed from the bottom to top in order to maximize revenue when demand is sufficient. The number of bookings authorized for sale in a specific class is determined by the airline’s RMS when maximizing revenue.

However, the simple class-based controls described above is not optimal for an airline with complex network traffic. For example, there are limitations in the number of classes (confined to 26 letters of the alphabet), difficulty in identifying points of sale and the fact that the classbased control system prices all seats within a class equally. The latter issue results in a loss in potential revenue if significant price differentiation opportunities are present intra-class. As such, many medium to large scale airlines are transitioning towards a revenue-based bid price control system that is more suitable to their network.

Unlike the class control method, revenue control is based on the profit generated by the sale of a seat. A bid price is defined as the minimum price at which the airline is willing to sell the current seat under consideration. The inventory management system regularly receives a set of bid prices (a "bid price vector” for a flight-cabin) calculated by the airline's RMS using future demand forecast and optimized fares in order to maximize revenue. After the inventory handling system is updated, seat confirmations are decided by comparing the bid price of the current seat under consideration against the fare assigned to the request, based on information (origin, destination, point of sale, travel dates etc.) associated with the availability request. An availability request for seat inventory can be produced by any channel in the airline's distribution network ${ }^{3}$ to confirm or execute a sale. If the fare assigned to the request exceeds the bid price, the seat is confirmed, and the system then proceeds to the subsequent seat and its

\footnotetext{
${ }^{3}$ Travel agency, airline website, other online sales, airline ticket offices, etc.
} 
corresponding bid price for the next sale. Otherwise, the current request is rejected. This procedure continuously assesses every seat request against the corresponding bid price in order to maximize revenue.

Figure 2 below displays a typical bid price vector of a flight-date at the cabin level. The vertical dashed line illustrates the current seat to be sold (e.g. the final $15^{\text {th }}$ seat of the flight is now under consideration for sale), and the horizontal dashed line is the bid price for said seat. The intersection point is the bid price/hurdle rate that the availability request must fulfill for the sale to be confirmed.

\section{Figure 2: Bid Price Vector of a Flight-Date}

Figure 2 presents the graph of a typical bid price vector of a flight-date vs seat numbers. The vertical axis represents the expected price (bid price/hurdle rate) and the horizontal axis represents the seat number. The current selling seat's bid price is determined at the intersection of the bid price vector and the current seat being sold. If there is high demand for the flight, a high hurdle rate is expected in order to segregate the market in order to maximize revenue. If there is considerably less demand than the capacity, the bid price/hurdle rate is expected to be zero, indicating that any fare is eligible to secure a seat as there is insufficient demand to fill the capacity. Figure 2 indicates that any fare above $\$ 48$ is sufficient to purchase the next seat available in the flight cabin.

\section{Bid Prices vs Seat Number}

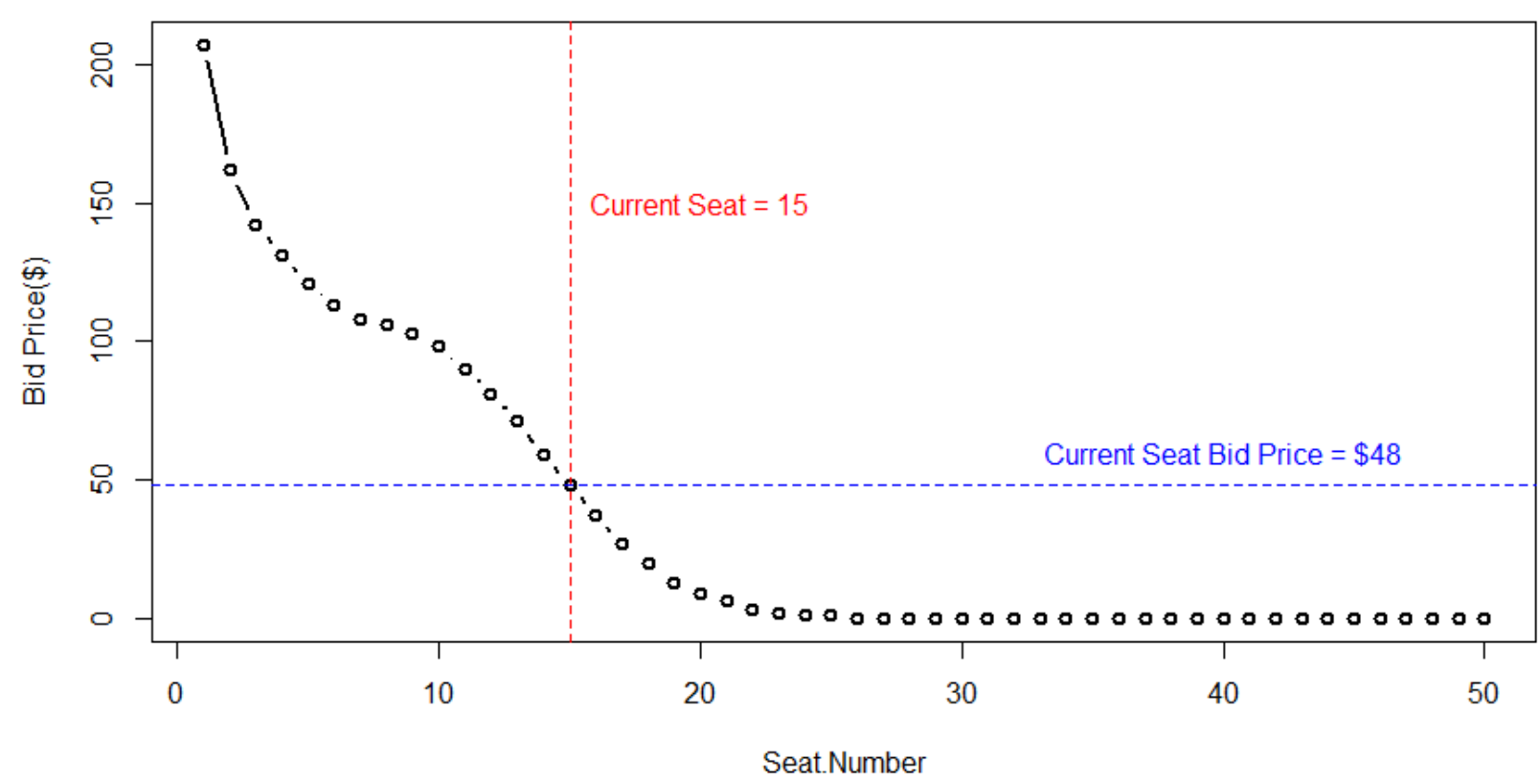

Bid prices are calculated for every flight-date cabin seat in the future booking window based on forecasted demand and the average predicted prices of all markets within the RMS optimizer module. When demand is high and seat availability is expected to be scarce, this process awards the next available seat to the highest-paying passenger. The bid prices will organically rise to 
accommodate only the highest paying passengers in times of high demand. If there is insufficient demand or excess capacity, the bid prices will equal zero and all passengers requesting availability will be allocated a seat. In a multi-sector travel (flow traffic) scenario, the flight-date-cabin bid prices at each sector are linearly added and compared with the request's end-to-end fares.

\section{FLOW TRAFFIC DEMAND ANDAIRFARES AS VALID INSTRUMENTAL VARIABLES}

The primary objective of this study is to implement and verify flight date-days to departure level flow traffic as a strong and valid instrumental variable when estimating price-demand elasticity. Elasticity is estimated for point-to-point markets, and the instruments are derived from flow traffic data.

We define point-to-point traffic as the direct demand between the two markets (A to B) considering direct travel starting from A and terminating at B. Any other traffic flows that travel between $\mathrm{A}$ and $\mathrm{B}$, though originating and/or terminating elsewhere, are considered as flow traffic (e.g. A-B-C, D-A-B, E-A-B-F).

As discussed in Section 4, flow traffic demand is factored in the optimizer when calculating bid prices. A flight-date-cabin with sufficient load factor is expected to exhibit a positive correlation between flow traffic and the bid price vector, as fewer seats available will result in a higher hurdle rate/bid price (Figure 2). Bid prices are applied to the entire flight-date-cabin regardless of whether passengers are point-to-point or flow traffic in determining the hurdle price required to attain the next seat. It is through this RMS procedure that flow traffic is correlated to airfare; that is, more (less) flow traffic on a flight will increase (decrease) the ticket price for point-topoint passengers.

In this study, flow traffic data are aggregated at the DCP level (see Section 3 for details). These are the ranges of days to departure as defined by the partner airline. Flow traffic consist of various O\&D markets. When aggregated at the DCP level, this forms a diversified portfolio of flow traffic passengers at each DCP. As such, we posit that the diversified O\&D market formed by aggregating flow traffic is independent of demand shocks in the point-to-point O\&D market. Moreover, the airline RMS treats ticket prices (bid price vector) for a flow passenger as dependent on their own O\&D market characteristics and are viewed as a separate market from 
the point-to-point passengers bid-price vector ${ }^{4}$. Given that individual flow passengers are viewed as independent of the point-to-point O\&D market by the RMS, aggregating and forming a diversified portfolio of flow traffic will result in a measure that is largely orthogonal to shocks in the point-to-point O\&D market. We will test this empirically using correlation measures and the Sargan (1988) test for overidentifying restrictions. The airfare of the flow passengers for their entire journey (extending beyond the point-to-point $\mathrm{O \& D}$ ) is employed as an additional instrumental variable.

First, as the point-to-point O\&D constitutes a segment in the flow passengers' journey, there naturally exists a slight correlation between the airfare of flow passengers and that of point-topoint passengers. Airlines view O\&D markets as being completely independent which is why often in practice the ticket price for A-B-C is not equal to the sum of the two separate ticket prices for A-B and B-C. However, correlation does exist between flow passenger airfares and that of point-to-point passengers ${ }^{5}$.

Second, the requested airfare for the entire journey of flow passengers is compared to the summation of the bid prices/hurdle rates of each segment of the flow itinerary. This results in flow passengers' ticket prices being substantially less sensitive to the point-to-point market’s bid price vector. As the flow passengers originate and end their journeys at different destinations, we posit that the DCP-averaged airfares for the portfolio of flow passengers are orthogonal to demand shocks in the point-to-point O\&D market ${ }^{6}$.

Though the instruments employed in this study are imperfect, from a practical application perspective, we posit that most of the correlations in the error term of the second stage equation and the proposed instruments stemming from seasonality, holidays and special events at the origin and destination have been accounted for by the vector of control variables at the second stage regression. Any remaining variation in the error term may not be perfectly orthogonal to the instruments, but for practical applications, they are relatively independent as supported by the statistical tests of this study.

\footnotetext{
${ }^{4}$ Ideally, only flow traffic that do not originate nor end at the O\&D of the point-to-point route should be considered as these will be completely orthogonal to the point-to-point O\&D market as neither the origin nor destination are shared. We thank the anonymous reviewer for this suggestion. However, this form of flow traffic constitutes less than 3 percent of passengers thus we use all flow O\&Ds under the assumptions stated below.

${ }^{5}$ The Spearman and Kendall correlations between point-to-point airfares and flow passengers' average airfares are 0.447 and 0.315 , respectively.

${ }^{6}$ The Spearman and Kendall correlations between point-to-point passenger demand and flow passengers' average airfares at the DCP-level are -0.041 and -0.031 , respectively.
} 
A strong and valid instrument should exhibit two properties: (1) it must be orthogonal to the error term (shocks in passenger demand in the point-to-point O\&D market), and (2) it must be correlated with the endogenous explanatory variable (point-to-point O\&D airfares). From a practical perspective, flow traffic and flow passenger airfares meet the above criteria and are thus suitable instrumental variables.

We create three instrumental variables using the flow traffic data:

(1). Cumulative Flow Demand - cumulative flow traffic at each days to departure range (DCP) at the flight date-days to departure level. This measure is cumulated from earlier days prior ranges and represent the flow traffic build up as departure approaches. This variable captures the number of seats already occupied by flow passengers at each DCP which invariably influences the bid price vector for point-to-point passengers.

(2). Flow Demand - Flow traffic demand observations at the flight date-days to departure (DCP) level. This can be viewed as the flow demand at the specific observation time (DCP). This variable represents the additional flow passengers that were allocated seats at each DCP. This instrument will be correlated with the change in the bid price vector for point-to-point passengers.

(3). Flow Demand Price - Average origin-and-destination price paid by flow traffic passengers at the flight date-days to departure level. This is the amount paid by flow traffic passengers for their end-to-end journey. As discussed above, this variable is correlated with point-to-point airfares yet unaffected by point-to-point demand shocks due to the portfolio effect at the DCP level and the mechanics of flow bid prices at the RMS.

The above variables are mapped to the observations and employed as instrumental variables in the 2SLS model.

\section{METHODOLOGY}

We employ a 2SLS model to account for the inherent endogenous relation between the regressor of interest and the dependent variable. The following model is applied to point-to-point public 
passengers for a select O\&D market. A log-log model specification is used to facilitate the estimation of elasticity. The first-stage regression is as follows

$$
\begin{aligned}
\text { FARE }_{\text {mijt }}= & \alpha_{0}+\text { TRAVEL_DOW } A_{1}+\text { BOOKING_DOW } A_{2}+\text { SEASON }_{j} A_{3} \\
& + \text { POS }_{m} A_{4}+D A Y S_{-} P R I O R_{t} A_{5}+\alpha_{6} C_{F L O W_{j t}}+\alpha_{7} F L O W_{j t} \\
& +\alpha_{8} A V G_{-} P R I C E_{j t}+\gamma_{\text {mijt }}
\end{aligned}
$$

where:

$F A R E_{\text {mijt }}$ is the natural logarithm of the average point-to-point $O \& D$ fare for each ticket that is purchased in point-of-sale city $m$ on the day of the week $i$ for flight-date $j$ at DCP time $t$;

TRAVEL_DOW $W_{j}$ is a vector of dummy variables capturing the fixed-travel day of the week effects for flight-date $j$;

BOOKING_DOW $i$ is a vector of dummy variables capturing the fixed-booking day of the week effects for the tickets that are purchased on the day of the week $i$;

$S E A S O N_{j}$ is a vector of dummy variables accounting for seasonality including holidays and special events in airfares as defined by the RMS applicable to the tickets for flight-date $j$;

$P O S_{m}$ is a vector of dummy variables accounting for point-of-sale city effects for the tickets that are purchased in point-of-sale city $m$;

$D A Y S \_P R I O R_{t}$ is a vector of dummy variables accounting days prior to departure categories as defined by the RMS for tickets that are DCP time $t$;

$C F L O W_{j t}$ is the cumulative flow traffic demand at each DCP range for flight-date $j$ at DCP time $t$;

$F L O W_{j t}$ is the average flow traffic demand for flight-date $j$ at DCP time $t$;

$A V G \_P R I C E_{j t}$ is the average ticket price of the flow traffic tickets for flight-date $j$ at DCP time $t$;

$\alpha_{k}$ is the regression coefficient for regressor $k$;

$A_{k}$ is a vector of regression coefficients for the vector of binary variables $k$;

$\alpha_{0}$ is the intercept term;

$\gamma_{m i j t}$ is the error term. 
The predicted values of $F A R E_{\text {mijt }}$, denoted by $F A \hat{R} E_{\text {mijt }}$, are produced from the estimates of (1) to capture price movements that are exogenous from shocks in demand in the $O \& D$ markets. The second stage regression is specified as:

$$
\begin{aligned}
\text { DEMAND } & D_{\text {mijt }}=\beta_{0}+\beta_{1} F A \hat{R} E_{m i j t}+\text { TRAVEL_DOW } B_{2}+\text { BOOKING_DOW } B_{3} \\
& + \text { SEASON } B_{4}+\text { POS }_{m} B_{5}+\text { DAYS_PRIOR } B_{t} B_{6} \\
& +\beta_{7} D E M A N D \_O T H E R_{\text {mijt }}+\varepsilon_{m i j t}
\end{aligned}
$$

where:

$D E M A N D_{\text {mijt }}$ is the natural logarithm of the number of public passengers who purchased a ticket in point-of-sale city $m$ on the day of the week $i$ for flight-date $j$ at DCP time $t$;

$F A \hat{R} E_{\text {mijt }}$ is the predicted value of the natural logarithm of the average point-to-point O\&D fare for each ticket that is purchased in point-of-sale city $m$ on the day of the week $i$ for flight-date $j$ at DCP time $t$, as estimated by (1);

TRAVEL_DOW $W_{j}$ is a vector of dummy variables capturing the fixed-travel day of the week effects for flight-date $j$;

BOOKING_DOW $i$ is a vector of dummy variables capturing the fixed-booking day of the week effects for the tickets that are purchased on the day of the week $i$;

$S E A S O N_{j}$ is a vector of dummy variables accounting for seasonality including holidays and special events in airfares as defined by the RMS applicable to the tickets for flight-date $j$;

$P O S_{m}$ is a vector of dummy variables accounting for point-of-sale city effects for the tickets that are purchased in point-of-sale city $m$;

$D A Y S \_P R I O R_{t}$ is a vector of dummy variables accounting days prior to departure categories as defined by the RMS for tickets that are DCP time $t$;

DEMAND_OTHER $R_{\text {mijt }}$ is the number of non-public passengers who purchased a ticket in point-of-sale city $m$ on the day of the week $i$ for flight-date $j$ at DCP time $t$; . $\beta_{k}$ is the regression coefficient for regressor $k$;

$\mathrm{B}_{k}$ is a vector of regression coefficients for the vector of binary variables $k$;

$\beta_{0}$ is the intercept term;

$\varepsilon_{m i j t}$ is the error term. 
The estimate of $\beta_{1}$ is the elasticity measure, ceteris paribus, that is robust to any potential endogeneity in the price-demand relationship.

\section{HIGH DEMAND AND INSTRUMENT STRENGTH}

The strength of flow traffic as an instrument depends on the relationship between the bid price and the number of seats available. If there is a strong relationship, then additional flow traffic will influence the bid price. However, there may exist instances where this relation may be nonexistent. First, if there is insufficient demand in a flight date-point of sale and booking datedays to departure observation, additional flow traffic will have little impact on bid prices as the bid price vector will be flat. This occurs as the inventory control mechanism adopts a low bid price for all seats to accept as many requests as possible. Second, the link between flow traffic and bid prices deteriorate in observations with low/non-existent levels of flow traffic as there is insufficient flow traffic to shift the bid price.

We propose dividing the data based on DEMAND $D_{\text {mijt }}$ and $F L O W_{\text {mijt }}$ into three simple groups as HIGH, LOW and ALL. The HIGH sample consists of observations that are in high demand and have a relatively high level of flow traffic. This sample will activate the link between flow traffic and airfares; thus, strengthening the proposed flow traffic instruments. The LOW sample consists of observations that exhibit both low passenger demand and flow traffic. The ALL sample includes all observations in the dataset. We posit that the 2SLS modelling procedure will be most effective in the HIGH demand sample due to the strength (relevance) of the instrument.

We sort the observations into quartiles on total passenger numbers and on the number of flow passengers. Due to the high dispersal of total passenger numbers, we define the HIGH sample as observations in the $4^{\text {th }}$ quartile and LOW sample as those in the $1^{\text {st }}$ quartile. Flow traffic exhibits less variation, and hence we define HIGH as observations with flow passengers in the top 50 percentile and LOW sample in the lowest 50 percentile. Table 1 below provides the statistics of the sample partition.

\section{Table 1: Statistics of total passengers and flow passengers}

The summary table below shows simple statistics of flights in this study based on total passengers and flow passengers. Flow traffic is defined as passengers that travel via the O\&D (A and $\mathrm{B}$, respectively) yet originate and/or terminate their trip at another destination, e.g. A-B-C, D-A-B, E-A-B-F. 


\begin{tabular}{l|cccccc}
\multicolumn{2}{l}{ Minimum } & 1st Quartile & Median & Mean & 3rd Quartile & Maximum \\
\hline Total Pax & 49 & 144 & 165 & 165.6 & 190 & 247 \\
Flow Pax & 2 & 29 & 40 & 41.01 & 53 & 92
\end{tabular}

Observations are grouped into the following categories:

1. LOW demand flights - first quartile of total passenger numbers (less than 144) and below the median value for flow traffic (40).

2. HIGH demand flight - fourth quartile of total passenger numbers (more than 190) and above the median value for flow traffic (40).

3. ALL - contains all observations in the dataset.

In the subsequent section, we compare the estimate results of all three samples.

\section{RESULTS}

We begin with the OLS and 2SLS elasticity regression estimates of equation (2), which are presented in Table 2 below. Note that the OLS regression does not account for the endogenous relation between price and demand. Control variables are unreported for the sake of brevity. The regression output is presented in the Table A2 of the Appendix. Models (a) and (b) are estimated using the full dataset. We can observe that the OLS price elasticity estimate in Model (a) of Table 2 is -0.1479 which suggests that the price-demand elasticity for the route is highly inelastic. From a practical standpoint and discussions with airline revenue managers, this is inconsistent with market observations for the route under consideration. Model (b) is the 2SLS estimate of (1) and (2), and accounts for endogeneity in the price-demand relationship. As such, the coefficient of FARE is expected to be a more accurate measure of elasticity as it corrects for endogeneity. The elasticity estimate increases markedly to -0.1955 but is still inelastic (larger than -1). 


\section{Table 2: OLS and 2SLS - Full Sample}

The summary table below presents the statistics of each model. There are 19703 observations considered in this sample from the specific route having 8 hours flying duration in the outbound market direction of a major Network Carrier. Control variables are unreported for the sake of brevity. Model (a) is Ordinary Least Square model (OLS) as defined by (2) without the instrumentation of FARE. Model (b) is Two Stage Least Squares model as detailed in equations (1) and (2). The full regression output is presented in Table A2 of the Appendix. HAC robust standard errors are contained in parentheses. The test for joint significance is the F-statistic for the OLS specification and the Wald statistic for the 2SLS specification. Model (b) employs instrumental variables as outlined in (1) for FARE. *, **, and *** denote statistical significance at the 10, 5, and 1 percent levels, respectively.

\begin{tabular}{|c|cc|}
\cline { 2 - 3 } \multicolumn{1}{c|}{} & $\begin{array}{c}\text { Model (a) OLS } \\
\text { Dependant Variable: Demand (point-to-point) }\end{array}$ \\
\hline FARE & $-0.148^{* * *}$ & Model (b): 2SLS \\
Constant & $(0.010)$ & $-0.196^{*}$ \\
Travel_DOW & $\sqrt{ }$ & $(0.082)$ \\
Booking_DOW & $\sqrt{ }$ \\
Season & $\sqrt{ }$ & $\sqrt{ }$ \\
POS & $\sqrt{ }$ & $\sqrt{ }$ \\
Days Prior & $\sqrt{ }$ & $\sqrt{ }$ \\
Instruments & $\sqrt{ }$ & $\sqrt{ }$ \\
R-square & 0.092 & $\sqrt{ }$ \\
Joint Significance & $32.091^{* * *}$ & 0.093 \\
\hline
\end{tabular}

We formally test for the presence of endogeneity in the price-demand relationship using the Durbin-Wu-Hausman (DWH) test for endogeneity and find that there is no endogeneity present in the full sample (see Unbiased test in the lower panel of Table A2 in the Appendix). This may be a symptom of the instrumental variables being ineffective in expunging the endogeneity in the price-demand relationship. As such, the analysis now focuses on the HIGH sample where we expect the instruments to have greater strength and variation.

The results for the HIGH sample are contained in Table 3. The OLS price elasticity in Model (a) of this sample is again inelastic at -0.3733 whereas Model (b) - the 2SLS estimates - reports an elasticity estimate of -1.1572 which is expected by the partner airline's revenue managers for the route in question, as empirically, passengers have been sensitive to price changes. Our elasticity estimate quantifies their behavior. Diagnostic tests, as reported in Table A2 of the 
appendix, suggest that Model (b) of the HIGH sample is well specified. The DWH test (Unbiasedness test in the lower panel for the HIGH sample) rejects the null hypothesis that the proposed instruments are unable to expunge the effect of endogeneity if it is present. As such, our instruments in the HIGH sample are able to identify and mitigate endogeneity. The first stage regressions suggest that the 2SLS estimates using the HIGH sample is more appropriate than using the full sample due to the strength of the instruments ${ }^{7}$. The first-stage regressions are jointly significant at the 1 percent level, as reported by the Strong Instruments statistic.

Finally, the Sargan (1988) test considers the exogeneity of the instrumental variables (Hausman, 1983; Parente and Silva, 2012). If the instruments are endogenous, and thus produce inconsistent parameter estimates, the overidentified moment restrictions may be systematically violated. The J-statistic follows a chi-squared distribution. The null hypothesis states that the instruments are orthogonal to the errors and in this case, it cannot be rejected at the 1 percent level. This suggests that the proposed instruments in the HIGH sample allow obtaining consistent estimates of the parameter vector of $(2)^{8}$.

Coupled with its consistency with practitioner intuition and observations from our partner airline, we recommend the elasticity estimate of -1.1572 for the route studied. The proposed 2SLS model will provide estimates of demand based on the elasticity measure of -1.1572 and incorporate demand variations from booking day of the week, travel day of the week, point of sale (city), seasonality, and days to departure.

\footnotetext{
${ }^{7}$ Results of the first-stage regressions are omitted for the sake of brevity. Contact the corresponding author for results.

${ }^{8}$ Nevertheless, this result should be taken with caution because overidentification tests have no power when the instruments are of the same nature, i.e. when they come from the same source, which may arguably be the case in this situation (see the discussion in De Blander, 2008; Guevara, 2018; Newey, 1985; Parente and Silva, 2012).
} 


\section{Table 3: OLS and 2SLS - High Demand flight sample}

The summary table below presents the statistics of models based on High Demand flight sample. There are 2985 observations considered in this sample from the specific route having 8 hours flying duration in the outbound market direction of a major Network Carrier. Control variables are unreported for the sake of brevity. Model (a) is Ordinary Least Square model (OLS) as defined by (2) without the instrumentation of FARE. Model (b) is Two Stage Least Squares model as detailed in equations (1) and (2). The full regression output is presented in Table A2 of the Appendix. HAC robust standard errors are contained in parentheses. The test for joint significance is the F-statistic for the OLS specification and the Wald statistic for the 2SLS specification. Model (b) employs instrumental variables as outlined in (1) for FARE. *, **, and *** denote statistical significance at the 10,5 , and 1 percent levels, respectively.

\begin{tabular}{|c|cc|}
\cline { 2 - 3 } \multicolumn{1}{c|}{} & $\begin{array}{c}\text { Model (a) OLS } \\
\text { Dependant Variable: Demand (point-to-point) }\end{array}$ & $\begin{array}{c}\text { Model (b): 2SLS } \\
\text { FARE }\end{array}$ \\
& $-0.373^{* * *}$ & $-1.157^{* * *}$ \\
Constant & $(0.031)$ & $(0.292)$ \\
Travel_DOW & $\sqrt{ }$ & $\sqrt{ }$ \\
Booking_DOW & $\sqrt{ }$ & $\sqrt{ }$ \\
Season & $\sqrt{ }$ & $\sqrt{ }$ \\
POS & $\sqrt{ }$ & $\sqrt{ }$ \\
Days Prior & $\sqrt{ }$ & $\sqrt{ }$ \\
Instruments & $\sqrt{ }$ & $\sqrt{ }$ \\
R-square & & 0.101 \\
Joint Significance & $8.991^{* * *}$ & $2.415^{* * *}$ \\
\hline
\end{tabular}

\section{DISCUSSION AND CONCLUSION}

This study is the first to produce unbiased price-demand elasticity measure at the flight datepoint of sale and booking date-days to departure level using individual ticketing data. We mitigate the endogeneity problems in estimation by identifying a novel instrumental variable: the flow passengers for an O\&D market. This is possible given the disaggregate nature of the dataset. Flow passengers, those that are travelling beyond the point-to-point O\&D of the market of interest, have an impact on airfares but are not subject to air travel demand shocks of the said O\&D market, thus making them ideal instruments in a 2SLS framework.

The findings suggest that the O\&D market of interest is elastic with an estimated elasticity of 1.157. Though this level of elasticity is consistent with the intuition of industry practitioners, our estimates provide revenue managers with precise quantifiable measures that can be used in their pricing strategies. The instrumental variables are theoretically valid and are highly relevant based on the F-test of the first-stage regression. Observations with both high ticket demand and 
flow traffic are ideal as they ensure that the instrumental variables are effective and provide more precise estimates of price-demand elasticity.

As the elasticity estimate is produced using the HIGH sample only (high passenger demand and high flow traffic), we recommend that this procedure is accurate in estimating passenger price sensitivity for such instances only. However, it is the high demand (high seat factor) flights that airlines' RMS can add substantial value; that is, it is these instances where understanding the elasticity of passengers is crucial. Airlines are savvy to which flight date-point of sale and booking date-days to departure instances are likely to exhibit high passenger demand and flow traffic.

Observations with low demand (low seat factor) will adopt a flatter bid price vector and award seats to almost all requests; hence, understanding elasticity in these low demand instances is less important. Our elasticity estimate may still provide an informative cross-sectional comparison of elasticity across routes, even if only applicable to HIGH samples.

The advantages of the proposed model are manifold. First, this model employs data at the flight date-point of sale and booking date-days to departure level and is able to estimate passenger demand subject to airfare while accounting for the number of days of the booking prior to departure, seasonality and special holidays, day of the week and time of departure ${ }^{9}$, city point of sale, day of travel, and day of booking. This level of granularity provides a unique insight into the demand characteristics of passengers, such as their sensitivity to the travel day of the week. Moreover, this study utilized booking and ticketing data from all the sales distribution channels rather than focusing on one channel (such as online) only. This allows for more generalizable findings.

Second, and importantly, this study is a first step in estimating granular elasticity measures conditional on days to departure, passenger type, city point of sale, etc using non-linear regression tools, such as interaction terms in (2). Analyzing elasticity at the ticketing-booking level allows for a deeper understanding of passengers’ dynamism in elasticity.

\footnotetext{
${ }^{9}$ Time of departure is represented in the flight number variable. However, the flight number variable is omitted in this analysis as there is only one flight number in the market under consideration. Nonetheless, a generalised version of this model within the proposed framework could include flight number/time of departure as a control variable.
} 
Third, the datasets employed (coupon, booking and ticketing) are readily available to airlines which means the proposed model is directly applicable to practitioners. We employ real data as used by our partner airline, and hence we are able to produce a model that is congruent with industry conventions, such as the demarcation of days prior to departure, identification of holidays and seasons, etc.

Note that the instrumental variables proposed are only applicable to flights under bid price control as this ensures the relation between flow traffic and airfares. Though many medium to large scale airlines are now under bid price $O \& D$ control, there are significant number of small airlines under class control ${ }^{10}$ whose price-demand elasticity cannot be estimated under the current 2SLS framework. However, as long as an airline utilizing bid price control is servicing a particular route, the elasticity of that O\&D should not deviate substantially across airlines, such that a smaller class control-based airline can confidently rely on the elasticity measure of another.

This study, alongside further research utilizing this data and 2SLS approach, will assist revenue managers in pricing their air travel products for specific markets. This will allow airlines to exploit the large datasets they have in their possession and operationalize them to improve their revenue management, and for researchers to better understand the airline consumer market and purchasing behavior.

\footnotetext{
${ }^{10}$ Refer to Section 4 for a brief review of class control and O\&D bid price control
} 


\section{APPENDIX}

\section{Table A1: Data Capturing Point (DCP) Ranges}

Ranges of data capturing points (DCP) used in this study represented below. The purpose of DCPs is to divide the booking period (0 to 355 days) into intervals during which the arrival rate has been historically constant. See McLaren et al. (2000) for details. Start (End) Days Prior is the number of days before departure for the start (end) of the DCP interval. Range is the number of days in the corresponding DCP interval.

\begin{tabular}{c|ccc}
\hline DCP & Start Days Prior & End Days Prior & Range \\
\hline 1 & 355 & 251 & 105 \\
2 & 250 & 168 & 83 \\
3 & 167 & 135 & 33 \\
4 & 134 & 98 & 37 \\
5 & 97 & 67 & 31 \\
6 & 66 & 47 & 20 \\
7 & 46 & 32 & 15 \\
8 & 31 & 23 & 9 \\
9 & 22 & 16 & 7 \\
10 & 15 & 12 & 4 \\
11 & 11 & 10 & 2 \\
12 & 9 & 9 & 1 \\
13 & 8 & 8 & 1 \\
14 & 7 & 6 & 2 \\
15 & 5 & 4 & 2 \\
16 & 3 & 3 & 1 \\
17 & 2 & 2 & 1 \\
18 & 1 & 1 & 1 \\
19 & 0 & 0 & 1 \\
\hline
\end{tabular}

\section{Table A2: OLS \& 2SLS - Full Sample}

The sample consists of 19703 observations covering 12 months departure window of the selected route in the outbound market direction of a large network carrier. Columns 2 and 3 contain the OLS and 2SLS estimates using the full dataset. Column 4 contains the parameter estimates for the 2SLS using the HIGH sample. HIGH sample consists of high demand and flow traffic observations as define in Section 7. The HIGH sample consists of 2985 observations. Seasonality and POS (city) dummy variables (other than O\&D markets) are omitted for the sake of brevity. Contact the authors for full results. HAC robust standard errors are contained in parentheses. ${ }^{* * *}$, and $* * *$ denote statistical significance at the 10,5 , and 1 percent levels, respectively. The Sargan test is the test for coherency in instruments. The test for weak instruments is the F-test of the first-stage regression, (1). The Durbin-Wu-Hausman test is the test for unbiasedness in the elasticity estimate. The test for joint significance is the Fstatistic for the OLS specification and the Wald statistic for the 2SLS specification. The 2SLS specification is (1) and (2). The OLS specification is (2). BBB and AAA are the origin and destination cities of the point-to-point market, respectively. 


\begin{tabular}{|c|c|c|c|c|c|c|}
\hline \multicolumn{7}{|c|}{ Dependent Variable: DEMAND } \\
\hline & \multicolumn{2}{|c|}{ (a) $O L S$} & \multicolumn{2}{|c|}{ (b) $2 S L S$} & \multicolumn{2}{|c|}{ (c) $2 S L S$ - HIGH } \\
\hline & Coefficient & Std Error & Coefficient & Std Error & Coefficient & Std Error \\
\hline \multicolumn{7}{|l|}{ Regressor } \\
\hline Constant & $0.796 * * *$ & 0.149 & 0.918 & 0.621 & $24.518^{* * *}$ & 4.377 \\
\hline FARE & $-0.148 * * *$ & 0.010 & $-0.196 * *$ & 0.082 & $-1.157 * * *$ & 0.292 \\
\hline Departure_DOW2 & -0.001 & 0.015 & -0.014 & 0.043 & 0.079 & 0.148 \\
\hline Departure_DOW3 & 0.007 & 0.015 & -0.013 & 0.043 & -0.149 & 0.122 \\
\hline Departure_DOW4 & 0.016 & 0.015 & 0.062 & 0.042 & $0.224^{* *}$ & 0.103 \\
\hline Departure_DOW5 & 0.015 & 0.015 & 0.011 & 0.044 & 0.187 & 0.128 \\
\hline Departure_DOW6 & 0.021 & 0.015 & $0.079 *$ & 0.043 & $0.287 * *$ & 0.116 \\
\hline Departure_DOW7 & $0.046^{* * *}$ & 0.015 & 0.064 & 0.043 & $0.822^{* * *}$ & 0.192 \\
\hline Booking_DOW2 & -0.014 & 0.014 & -0.018 & 0.045 & -0.015 & 0.121 \\
\hline Booking_DOW3 & $-0.041^{* * *}$ & 0.014 & -0.031 & 0.045 & -0.064 & 0.114 \\
\hline Booking_DOW4 & -0.021 & 0.014 & -0.068 & 0.044 & -0.184 & 0.113 \\
\hline Booking_DOW5 & $-0.038 * * *$ & 0.014 & -0.057 & 0.044 & -0.053 & 0.114 \\
\hline Booking_DOW6 & $-0.056^{* * *}$ & 0.016 & $-0.086 *$ & 0.049 & -0.167 & 0.13 \\
\hline Booking_DOW7 & $-0.063^{* * *}$ & 0.016 & $-0.084^{*}$ & 0.048 & -0.093 & 0.13 \\
\hline POScityAAA & $0.404 * * *$ & 0.100 & $0.617^{*}$ & 0.335 & -0.204 & 0.648 \\
\hline POScityBBB & 0.161 & 0.100 & 0.301 & 0.333 & -0.376 & 0.647 \\
\hline$D P 2$ & $0.123 * * *$ & 0.029 & $0.353^{* * *}$ & 0.104 & 0.251 & 0.413 \\
\hline$D P 3$ & $0.077 * * *$ & 0.029 & $0.256^{* *}$ & 0.11 & 0.479 & 0.41 \\
\hline$D P 4$ & $0.085^{* * *}$ & 0.027 & $0.222^{* *}$ & 0.101 & 0.14 & 0.39 \\
\hline DP5 & $0.079 * * *$ & 0.026 & $0.290 * * *$ & 0.097 & 0.424 & 0.385 \\
\hline DP6 & $0.055^{* *}$ & 0.026 & $0.301^{* * *}$ & 0.097 & 0.292 & 0.381 \\
\hline$D P 7$ & -0.028 & 0.026 & 0.121 & 0.097 & 0.116 & 0.378 \\
\hline$D P 8$ & $-0.089 * * *$ & 0.027 & 0.113 & 0.098 & 0.251 & 0.38 \\
\hline DP9 & $-0.157 * * *$ & 0.027 & 0.089 & 0.1 & 0.31 & 0.385 \\
\hline DP10 & $-0.138^{* * *}$ & 0.03 & 0.126 & 0.106 & 0.449 & 0.406 \\
\hline DP11 & $-0.153^{* * *}$ & 0.034 & 0.11 & 0.122 & 0.089 & 0.411 \\
\hline DP12 & $-0.173^{* * *}$ & 0.043 & 0.002 & 0.151 & 0.462 & 0.526 \\
\hline$D P 13$ & $-0.197 * * *$ & 0.042 & 0.027 & 0.132 & 0.09 & 0.463 \\
\hline DP14 & $-0.148 * * *$ & 0.034 & 0.076 & 0.114 & -0.004 & 0.441 \\
\hline DP15 & $-0.107^{* * *}$ & 0.033 & $0.189 *$ & 0.11 & 0.39 & 0.407 \\
\hline DP16 & $-0.129 * * *$ & 0.043 & 0.152 & 0.137 & 0.479 & 0.438 \\
\hline$D P 17$ & $-0.142 * * *$ & 0.041 & 0.116 & 0.13 & 0.476 & 0.45 \\
\hline DP18 & $-0.107^{* * *}$ & 0.04 & $0.274^{* *}$ & 0.128 & 0.334 & 0.438 \\
\hline DP19 & $-0.298 * * *$ & 0.076 & - & - & - & - \\
\hline Demand_Other & $0.064 * * *$ & 0.019 & 0.031 & 0.062 & $-3.275^{* * *}$ & 0.622 \\
\hline$R$-Squared & 0.092 & & 0.093 & & 0.101 & \\
\hline Joint Significance & $32.091^{* * *}$ & & $4.643^{* * *}$ & & $2.415^{* * *}$ & \\
\hline Unbiased & N/A & & 0.586 & & $9.535^{* * *}$ & \\
\hline Strong Instruments & N/A & & $191.399 * * *$ & & $25.515^{* * *}$ & \\
\hline Sargen Test & N/A & & 0.049 & & 1.528 & \\
\hline
\end{tabular}




\section{REFERENCES}

Berkowitz, D., M. Caner, and Y. Fang, (2008) “Are 'Nearly Exogenous’ Instruments Reliable?” Economics Letters 101, 20-23.

Currie, C.S.M. and Simpson, D. (2007), “Optimal pricing ladders for the sale of airline tickets”, Journal of Revenue and Pricing Management, 8(1), 96-106.

Fiig, T., Isler, K., Hopperstad, C. and Belobaba, P. (2009), "Optimization of mixed fare structures: Theory and applications”, Journal of Revenue and Pricing Management, 9, 152-170

Granados, N., Gupta, A., Kauffman, R. J. (2012), “Online and Offline Demand and Price Elasticities: Evidence from the Air Travel Industry”, Information Systems Research, 23(1), pp. 164-181, (C2012 INFORMS

Guevara, C. A., and Polanco, D. (2016), "Correcting for endogeneity due to omitted attributes in discrete-choice models: the multiple indicator solution, Transportmetrica A: Transport Science, 12:5, 458-478, DOI: 10.1080/23249935.2016.1147504

Hausman, J. A., (1983), “Specification and Estimation of Simultaneous Models”, Handbook of Econometrics, vol. 1. North-Holland, Amsterdam.

International Air Transport Association (2013), "Profitability and the air transport value chain”, IATA Economics Briefing, 10, 1-49.

Kaufman, L, Rousseeuw PJ (1990), “Finding Groups in Data: An Introduction to Cluster Analysis”, JohnWiley \& Sons, New York.

Lurkin, V., Garrow, L. A., Higgins, M. J., Newman, J. P. and Schyns, M. (2017), “Accounting for price endogeneity in airline itinerary choice models: An application to Continental U.S. markets”, Transportation Research Part A: Policy and Practice, 100 (2017) 228246

Lurkin, V., Garrow, L., Higgins, M., Schyns, M., (2015) “Estimation of Airline Itinerary Choice Models Using Disaggregate Ticket Data”, AGIFORS Annual Symposium August 2015, Washington DC

McLaren, C. E., Kambour, E. L., McLachlan, G. J., Lukaski, H. C., Li, X., Brittenham, G.E., and McLaren, G. D. (2000), "Patient-specific Analysis of Sequential Haematological Data by Multiple Linear Regression and Mixture Distribution Modelling”, Statistics in Medicine, 19, 83-98

Morrel, P. S. (2013), Airline Finance, Ashgate Publishing.

Mumbower, S., Garrow, L.A., Higgins, M.J. (2014), “Estimating Flight-Level Price Elasticities Using Online Airline Data: A First Step Toward Integrating Pricing, Demand, and Revenue Optimization”, Transportation Research Part A: Policy and Practice, 66 (2014) 196-212

Njegovan N. (2006), "Elasticities of demand for leisure air travel: A system modelling approach”, Journal of Air Transportation Management (2006) 12, 33-39. 
Parente P. M. D. C, and Santos Silva, J. M. C. (2012), "A cautionary note on tests of overidentifying restrictions”, Economics Letters, 115, 314-17.

Puller, S. L., and Taylor, L. M. (2012), "Price discrimination by day-of-week of purchase: Evidence from the U.S. airline industry", Journal of Economic Behavior \& Organization, 84, 3, 801-812.

Sargan, J., (1988), “Testing for misspecification after estimation using instrumental variables”, In Contributions to econometrics: John Denis Sargan, ed. E. Maasoumi, vol. 1. Cambridge University Press.

Seetraram, N. (2010), “Computing airfare elasticities or opening Pandora’s box”, Research in Transportation Economics, 26 (2010) 27-36

Weiss, R. M., and Mehrotra, A. K. (2011), “Online dynamic pricing: Efficiency, equity, and the future of e-commerce", Virginia Journal of Law and Technology, 11, 1-11.

Yadav, A. and Singh, S. (2013), "Study of K-Means and enhanced k-means clustering Algorithm”, International Journal of Advanced Research in Computer Science, Sep 2013, Vol.4(10) 